\title{
Dissatisfaction with life and associated factors in older community-dwelling adults
}

\author{
Annelita Almeida Oliveira Reiners' ${ }^{1 D}$ \\ Rosemeiry Capriata de Souza Azevedo' (ID \\ Joana Darc Chaves Cardoso' $\mathbb{1 D}$ \\ Mariano Martinez Espinosa ${ }^{2}$ (D) \\ Aenne Zandonadi Rodrigues Santana' $\mathbb{D}$
}

\section{Abstract}

Objective: To analyze the prevalence of dissatisfaction with life and associated sociodemographic factors. Method: A cross-sectional, population-based study was carried out. Data collection was performed using the Brazil Old Age Schedule (BOAS) questionnaire. A total of 573 older adults from the urban area were interviewed, selected through cluster sampling, stratified by sex. Bivariate analysis was performed using the chi-square and prevalence ratio with a 95\% confidence interval (CI). For multivariate analysis, the Poisson Robust regression model was applied. Variables were entered into the model using the backward method. Results: The prevalence of dissatisfaction with life was $15.53 \%$. Dissatisfaction with life was associated with women ( $P R=1.54 ; 95 \%$ CI: 1.02; 2.32), being illiterate ( $P R=2.57 ; 95 \% \mathrm{CI}: 1.44 ; 4.60)$, having up to four years of schooling (PR=1.79; 95\% CI: 1.01; 318) and having an income of less than two minimum wages $(\mathrm{PR}=3.29 ; 95 \% \mathrm{CI}: 1.29 ; 8.42)$. In the multivariate analysis, being female ( $\mathrm{PR}=1.50$; $95 \%$ CI: $1.01 ; 2.25)$, being illiterate ( $P R=2.54 ; 95 \% \mathrm{CI}: 1.42 ; 4.54)$ and having up to four years of schooling ( $\mathrm{PR}=1.77$; $95 \% \mathrm{CI}$ : $0.99 ; 3.14)$ remained associated with dissatisfaction with life Conclusion: the prevalence of dissatisfaction is low. Dissatisfaction with life was associated with sex, education and income, in a bivariate manner. Sex and education were predictors of dissatisfaction with life. These findings reinforce the need for actions to promote social equality between men and women and to facilitate the access of older adults to education.
Keywords: Health of the Elderly. Personal Satisfaction. Health Promotion.

\footnotetext{
Universidade Federal de Mato Grosso, Faculdade de Enfermagem, Departamento de Enfermagem. Cuiabá, MT, Brasil.

2 Universidade Federal de Mato Grosso, Departamento de Estatística. Cuiabá, MT, Brasil.
}

The authors declare there are no conflicts of interest in relation to the present study.

No funding was received in relation to the present study. 


\section{INTRODUCTION}

Discussion of the satisfaction that people have with life has grown in recent years ${ }^{1}$. It is a question of particular relevance for gerontology, as it is closely linked to healthy aging. Most studies related to this theme have been carried out in developed countries ${ }^{2,3}$, however, and the subject has only recently attracted interest in developing countries ${ }^{4,5}$.

In these countries, population aging is occurring rapidly, with implications for different areas of society ${ }^{6}$. As a result, government and health policies have been created that aim to support this segment of the population. Analysis of the satisfaction with life of older adults is therefore of interest as it helps to achieve the objectives proposed in these policies. In addition, it provides additional information on the specificities of older adults who live in countries with different economic and social configurations to developed nations.

Life satisfaction is the subjective judgment that an individual makes about their own life and is an important indicator of a person's quality of life ${ }^{7}$, being influenced by sociodemographic, economic and health factors, among others ${ }^{8-10}$. It is a complex phenomenon, assessed as a whole or in relation to a specific aspect of people's lives and/or health.

Surveys conducted with older adults have investigated the satisfaction of this group with life in general ${ }^{8.9}$, as well as in relation to certain aspects of life, such as old age, physical health, family relationships and the ability to solve problems ${ }^{8.10}$.

In Brazil, literature on satisfaction with life among the older population remains scarce ${ }^{8.9}$. Specifically, no study was found with a focus on the dissatisfaction with life of this segment of the population. Studies of this type are relevant insofar as they reveal the aspects that cause an individual to feel dissatisfied with their life, and may have a direct impact on various aspects of their life and well-being.

Thus, the following questions were asked: What is the prevalence of dissatisfied older adults? What factors are associated with older adults' dissatisfaction with life? In view of the above, the objective of the present study was to analyze the prevalence of dissatisfaction with life and associated sociodemographic factors in older residents in the community.

\section{METHOD}

A cross-sectional study, based on a household survey, was carried out in the city of Cuiabá, Mato Grosso, Brazil, which has a population of 45,632 older adults ${ }^{11}$. The study included all people aged 60 or over, living in the urban area of the city. Institutionalized older adults (those living in Long Term Care Facilities for Older Adults, hospitals, prisons, convents, hostels, and shelters) did not participate, along with older adults with cognitive difficulties, such as changes in orientation, memory, attention and language, as assessed by the Mini Mental State Examination (MMSE), or any other condition that would prevent them from answering the questions.

The sampling was probabilistic in nature and a finite population was considered to determine the sample size, using the following equation:

$$
\mathrm{n}=\frac{\mathrm{n}^{*}}{1+\left(n^{*} / N\right)}
$$

where $n^{*}$ is given by the equation (2):

$$
n^{*}=\frac{p(1-p)}{V(p)}
$$

With $V(p)=(d / z) 2$ where $p$ is the proportion of the characteristic to be estimated, $z$ the value in the standard normal curve, corresponding to the confidence coefficient used, $d$ the sampling error and $n$ the size of the studied population. A 95\% confidence coefficient $(z=1.96)$, 5.00\% sampling error, and $p$ value of $0.5(p=0.5)$ were adopted, which allowed a greater approximation to the value of the variance of the characteristic in the population, and thus, a greater sample size. Therefore, using the number of older adults living in the urban area of Cuiabá $(\mathrm{N}=43,096)$ and the equation (1), the approximate minimum sample size was 381 older adults. 
From the cluster sampling, a usual design effect of 1.5 was considered, that is, a correction in the sample size of $50 \%$ to achieve the desired precision of the research, giving a total of 573 older adults.

In order to determine the number of individuals to be interviewed in the urban districts of the municipality, the total number of older adults was considered and a stratification by sex was performed as follows: Cuiabá District: 288 older adults (124 men and 163 women); Coxipó da Ponte District: 285 older adults (130 men and 156 women).

The number of census sectors to be visited in each district was determined using cluster sampling, using the following calculation:

$$
c_{i}=\frac{N_{i}}{C_{i}} * n_{i}
$$

where $c i$ is the number of census sectors to be visited in each district ( $i=1$ or 2 ), $N i$ the number of older adults in each district, $C i$ the number of sectors in each district and $n i$ the number of older adults in the sample in each district. Thus, from 355 census sectors in the Cuiabá District, five were selected, and from 437 in the Coxipó da Ponte District, six were selected, totaling 11 census sectors.

When defining the number of census sectors drawn in each district, the criterion of probability proportional to the size of the population of each census sector was defined for the probabilities of each one being drawn, as they have a different number of older adults.

Data were collected through interviews, using the BOAS Questionnaire (Brasil Old Age Schedule) ${ }^{12}$. This is a multidimensional instrument, composed of nine sections on different aspects of the life and health of this population.

The interviews were conducted by trained individuals and strategies were used to ensure the reliability of the data (preparation of a data collection manual, standardization of the data collection form, selection and training of the interviewers, direct monitoring of the researchers in the field and a weekly review of the completion of the questionnaires).
The dependent variable analyzed in the present study was satisfaction with life, obtained from the question: How do you feel about your life in general?, categorized as Satisfied or Dissatisfied. The independent variables were: sociodemographic sex (male; female), age (60 to 69 years; 70 to 79 years; 80 years and over), years of schooling (over 4 years of study; up to 4 years of study, illiterate), marital status (married/partner; single/divorced; widowed), income (more than 3 minimum wages; 2 to 3 minimum wages; less than 2 minimum wages), currently working (yes; no), living arrangements (lives alone; lives with others) and presence of children (yes; no).

The data obtained were organized and processed in a database with the aid of a statistical program.

Initially, the associations between the dependent variable and the independent variables were assessed in a bivariate manner, using the Chi-square test and the prevalence ratio (crude prevalence ratio (PR)) with their respective $95 \%$ confidence intervals (95\% CI)). Next, the Poisson regression model was used to assess the multivariate association between the outcome variable and the independent variables, obtaining the adjusted prevalences. All independent variables or factors with a $p<0.20$ value in the bivariate analysis were entered in this model. For the entry of variables in the model, the backward method was used.

The research project was approved by the Research Ethics Committee of the Hospital Universitário Júlio Muller under protocol number 135 CEP-HUJM/11. All the participants signed an Informed Consent Form (ICF) before the interview.

\section{RESULTS}

Of the studied population ( $\mathrm{n}=573), 319(55.67 \%)$ were female and 254 (44.33\%) were male. The age of the older adults varied between 60 and 112 years $(95 \% \mathrm{CI}=70.86 ; 72.24)$, with a mean of $71.55( \pm 8.38)$ years. A total of $268(54.10 \%)$ individuals were in the 60 to 69 years old age range. In terms of marital status, $310(54.10 \%)$ were married or had partners and 416 older adults $(72.60 \%)$ could read and write. 
Regarding the satisfaction of older adults with life in general, 484 (84.47\%) reported being satisfied. Dissatisfaction with life was reported by 89 older adults $(15.53 \%)$. The main reasons for such dissatisfaction were health problems $(75.90 \%$, men and 64.30\%, women) and economic problems (44.80\%, men and 50.00\%, women) (Figure 1).

The risk factors for dissatisfaction with life were being female, being illiterate, having up to four years of schooling and having an income below two minimum wages. Women showed a prevalence of dissatisfaction with life of $18.24 \%$ and had a 0.54 times greater risk of being dissatisfied than men $(p=$ 0.036). Older adults with up to four years of schooling had a 0.79 times greater risk of being dissatisfied with life when compared to older people with more than four years of schooling and a 1.57 times greater risk than illiterates ( $p=0.042, p \leq 0.001$, respectively). As for income, older adults who earned less than two minimum wages were 2.29 times more at risk of being dissatisfied with life than those with more than three minimum wages $(p=0.007)$ (Table 1 ).

In the multivariate analysis, the variables that remained associated with dissatisfaction with life were sex and years of schooling (Table 2). Women were 0.50 times more at risk of being dissatisfied with life than men. Illiterate older adults were 1.54 times more at risk of being dissatisfied with life than those with more than four years of study, while those with up to four years of schooling had a 0.77 times greater risk (Table 2).

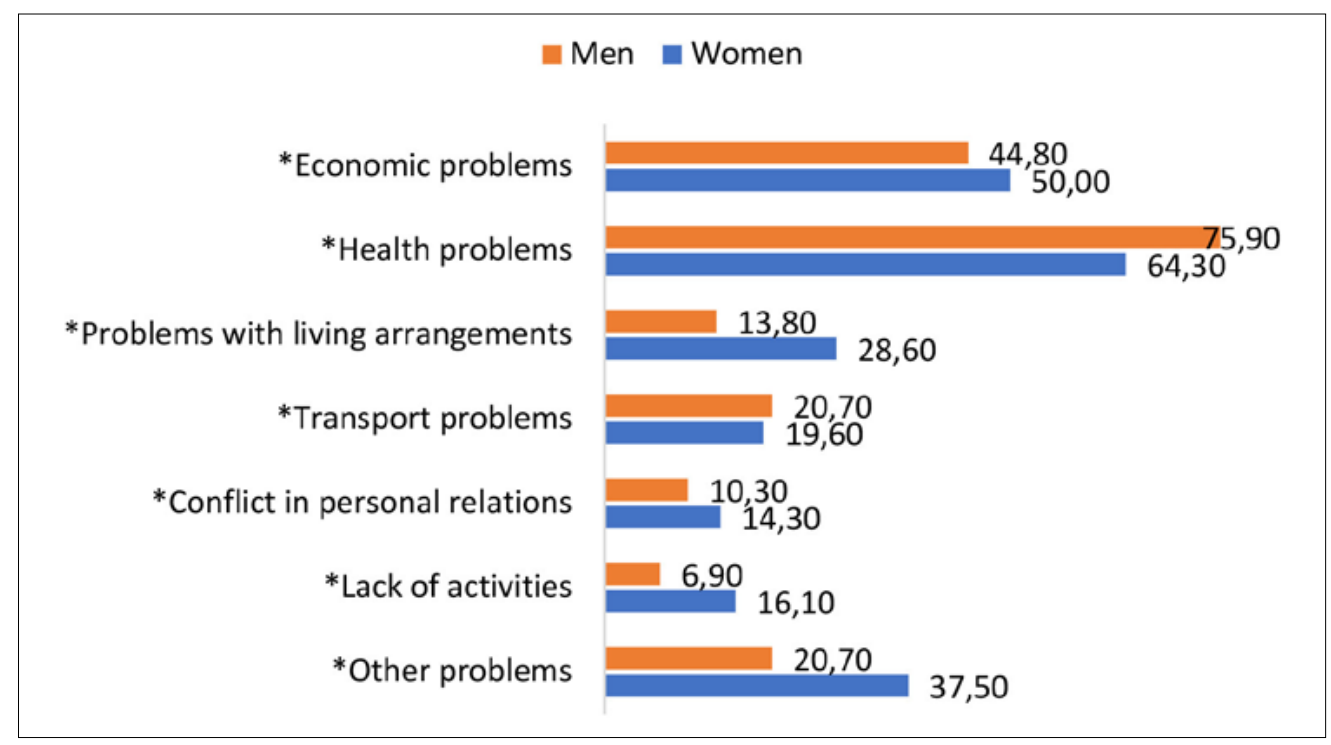

*Multiple choice variable, the older adults can choose more than one reason for dissatisfaction with life.

Figure 1. Reasons for dissatisfaction with life of older adults according to sex. Cuiabá, Mato Grosso, 2012. 
Table 1. Association of dissatisfaction with life among older adults and sociodemographic characteristics $(\mathrm{N}=573)$. Cuiabá, Mato Grosso, 2012.

\begin{tabular}{|c|c|c|c|c|c|}
\hline \multirow[b]{2}{*}{ Variables } & \multicolumn{5}{|c|}{ Satisfaction with life } \\
\hline & $\begin{array}{l}\text { Dissatisfied } \\
\mathrm{n}(\%)\end{array}$ & $\begin{array}{l}\text { Satisfied } \\
\text { n }(\%)\end{array}$ & $\mathrm{PRb}$ & $(95 \% \mathrm{CI})$ & $p$ \\
\hline \multicolumn{6}{|l|}{ Sex } \\
\hline Male & $30(11.81)$ & $224(88.19)$ & 1.00 & & \\
\hline Female & $59(18.50)$ & $260(81.50)$ & 1.54 & {$[1.02 ; 2.32]$} & 0.036 \\
\hline \multicolumn{6}{|l|}{ Age (years) } \\
\hline $60-69$ & $45(16.79)$ & $223(83.21)$ & 1.00 & & \\
\hline $70-79$ & $30(14.85)$ & $172(85.15)$ & 0.89 & {$[0.58 ; 1.36]$} & 0.583 \\
\hline 80 or over & $14(13.59)$ & $89(86.41)$ & 0.81 & {$[0.47 ; 1.42]$} & 0.460 \\
\hline \multicolumn{6}{|l|}{ Years of schooling } \\
\hline Over 4 & $14(8.75)$ & $146(91.25)$ & 1.00 & & \\
\hline Up to 4 & $40(15.63)$ & $216(84.38)$ & 1.79 & {$[1.01 ; 3.18]$} & 0.042 \\
\hline Illiterate & $35(22.29)$ & $122(77.71)$ & 2.57 & {$[1.44 ; 4.60]$} & $<0.001$ \\
\hline \multicolumn{6}{|l|}{ Marital status } \\
\hline Married/common-law marriage & $43(13.87)$ & $267(86.13)$ & 1.00 & & \\
\hline Widow/widower & $35(20.00)$ & $140(80.00)$ & 1.47 & {$[0.98 ; 2.21]$} & 0.067 \\
\hline Single/Separated/ Divorced & $11(12.50)$ & $77(87.50)$ & 0.92 & {$[0.49 ; 1.70]$} & 0.782 \\
\hline \multicolumn{6}{|l|}{ Income (minimum wage) } \\
\hline Over 3 & $5(5.38)$ & $88(94.62)$ & 1.00 & & \\
\hline 2 to 3 & $66(15.53)$ & $359(84.47)$ & 1.77 & {$[0.74 ; 4.21]$} & 0.176 \\
\hline Less than 2 & $18(32.73)$ & $37(67.27)$ & 3.29 & {$[1.29 ; 8.42]$} & 0.007 \\
\hline \multicolumn{6}{|l|}{ Currently working } \\
\hline Yes & $16(11.35)$ & $125(88.65)$ & 1.00 & & \\
\hline No & $73(16.90)$ & $359(83.10)$ & 1.48 & {$[0.89 ; 2.45]$} & 0.124 \\
\hline \multicolumn{6}{|l|}{ Living arrangement } \\
\hline Lives with others & $78(15.26)$ & $433(84.74)$ & 1.00 & & \\
\hline Lives alone & $11(17.74)$ & $51(82.26)$ & 1.09 & {$[0.60 ; 1.99]$} & 0.776 \\
\hline \multicolumn{6}{|l|}{ Presence of children } \\
\hline Yes & $86(16.10)$ & $448(83.90)$ & 1.00 & & \\
\hline No & $3(7.69)$ & $36(92.31)$ & 0.34 & {$[0.09 ; 1.31]$} & 0.081 \\
\hline
\end{tabular}

PRb: Gross prevalence ratio, 95\%, CI: 95\% confidence interval, p: Significance level considering Chi-Square distribution. 
Table 2. Distribution of prevalence of dissatisfaction with life and gross and adjusted prevalence ratio (PR) by Poisson Robust regression, with respective 95\% confidence intervals (CI) and value of p of the variables selected by the backward method (N=573). Cuiabá, Mato Grosso, 2012.

\begin{tabular}{llll}
\hline Variables & PRa & $(95 \% \mathrm{CI})$ & Value $p$ \\
\hline Sex & & & - \\
Male & 1.00 & - & 0.049 \\
Female & 1.50 & 1.01 to 2.25 & - \\
Years of schooling & & & - \\
Over 4 & 1.00 & - & 0.053 \\
Up to 4 & 1.77 & 0.99 to 3.14 & 0.002 \\
Illiterate & 2.54 & 1.42 to 4.54 & \\
\hline
\end{tabular}

PRa: Prevalence ratio adjusted in the Poisson regression model with selection of variables, ${ }^{*}$ Significant at a $5 \%$ level, CI: confidence interval.

\section{DISCUSSION}

The prevalence of dissatisfaction with life found in this study $(15.53 \%)$ is similar to findings from other studies conducted in Brazil. In a municipality in the interior of Bahia, $14.2 \%$ of older adults surveyed said they were dissatisfied ${ }^{13}$, as well as $18 \%$ of older adults in the city of Belo Horizonte ${ }^{14}$. This result is similar to a study carried out in Nepal, in which the authors found $21 \%$ of older adults were dissatisfied with life ${ }^{15}$. These findings show that, in general, only a small portion of the population tends to be dissatisfied with their lives.

Satisfaction with life can be assessed in different ways, including objective aspects, such as work, income, education, access to services and capacity of consumption, as well as economic, political and professional factors ${ }^{4,16}$.

Another aspect to be considered when people are asked about their satisfaction with life are subjective aspects, which involve affective and cognitive components ${ }^{17}$. In old age, considering the changes characteristic of aging, the assessment of older adults about their lives can be influenced by a decline in these components ${ }^{16,18}$.

However, research has revealed that older people tend to judge their lives positively through considering them over time, comparing them to the lives of others, and assessing their ability to control the environment and themselves, as well as their health, income and social network, among other factors $^{14}$. Thus, the low prevalence of older adults dissatisfied with their life may be related to the fact that several elements were taken into account in the evaluations of the studied group.

Evidence shows that some sociodemographic variables, such as the female sex ${ }^{19}$, being widowed ${ }^{19}$, a low income ${ }^{19}$, and low levels of education ${ }^{19.20}$ are associated with dissatisfaction with life. In the present study, the female sex remained positively associated with dissatisfaction with life. This result is consistent with those of other studies ${ }^{9,19}$. Several conditions, such as marriage, pregnancy, children's education, health, work and socioeconomic inequality, can influence the way women feel about their lives $8,21,22$.

Another important finding of the present study was that women reported greater dissatisfaction with life due to health and economic problems. This result was also found in previous studies carried out with older women ${ }^{8,19}$. Women are more affected by chronic and disabling morbidities ${ }^{23,24}$, while greater longevity exposes women to the deleterious effects of disease for longer ${ }^{25}$. Their economic problems, meanwhile, may be related to the fact that older women generally have lower incomes, which exposes them to social inequality ${ }^{24,26}$.

However, investigations have found that dissatisfaction with life is not always related to women $^{16,27}$. It can occur due to the differences that men and women attribute to their lives, such as values and perceptions, in addition to the different roles they occupy in society ${ }^{24}$. 
The strong association between dissatisfaction with life and years of schooling found in the present study may be related to the influence that education has on people's satisfaction with life ${ }^{14,19}$. Having more years of schooling favors access to information and the job market, leading to better paid jobs, and consequently, better quality of life and health ${ }^{4}$.

It is important to emphasize that the population of this study has predominantly low levels of education. The participants school years came at a time when the incentive to study and access to formal education was not encouraged, especially for women, who were usually raised for marriage and childcare ${ }^{24,28}$. Thus, the studied group may not have had the opportunities and benefits that formal education can offer and it is possible that this situation contributed to their unsatisfactory assessment of life.

Surprisingly, due to the frequency with which income appears in studies, this factor was associated with dissatisfaction with life, but when analyzed in the model it lost its effect, leaving only sex and education. According to literature ${ }^{14}$, a higher correlation was found between satisfaction with life and income, rather than education. For the authors, the association between satisfaction with life and income can be explained by its influence on people's quality of life.

In the case of older adults, greater income can mean greater access to goods, which provide greater quality of life and health at this stage of life. In addition, higher levels of education can improve the knowledge of older adults about making more suitable choices for their life and health and adopting healthy lifestyle habits, as well as providing access to information and services and higher incomes. However, insufficient economic resources may not allow the older person to benefit from these options ${ }^{14}$.

The present study provides important results on the lives of older adults in a developing country. In this sense, it contributes to the expansion of the scientific knowledge about older adults in these countries and their quality of life. In demonstrating the prevalence of dissatisfaction with life of older adults and the factors associated with it, it supports other studies in constructing a greater understanding of the aging process. In addition, the study includes a large and representative sample of older adults living in an urban area, which allows generalizations for the reference population of the study.

The present study has limitations, as it did not include people who lived in the countryside, and its results therefore apply only to older adults living in urban areas. It may be that older adults living in rural areas would evaluate their lives differently.

\section{CONCLUSION}

The prevalence of dissatisfaction in the present study was $15.53 \%$. In the bivariate analysis, the categories associated with dissatisfaction with life were the female sex, having up to four years of schooling, being illiterate and having an income of less than two minimum salaries. When analyzed together, in the multivariate analysis, income lost its effect, with only being female, being illiterate and having up to four years of schooling remaining in the final model. Thus, the variables sex and education were predictors of dissatisfaction with life.

Actions that promote social equality between men and women, such as equal earnings, are necessary to improve satisfaction with life among older adults. In addition, it is essential to create strategies to facilitate and favor the access to education services of older adults.

The results of the present study provide important contributions to the literature on satisfaction with life in developing countries, since it provides information on the specificities of these older adults. Considering such specificities, the government and health professionals can promote strategies to improve the living conditions of older adults, through groups in health units and social centers, aiming to develop activities that allow the discussion of gender and guaranteeing access to formal and financial education.

\section{ACKNOWLEDGMENTS}

The authors would like to thank Cecília Victorazzo Louzada (in memoriam), for her contribution to the creation of the present study, notably in the following activities: conception and planning, data collection, analysis and interpretation.

Edited by: Ana Carolina Lima Cavaletti 


\section{REFERENCES}

1. World Health Organization. Measurement of and target-setting for well-being:an initiative by the WHO regional office for Europe. Paris: WHO; 2013.

2. Boyce CJ, Delaney L, Wood AM. The great recession and subjective well-being: how did the life satisfaction of people living in the United Kingdom change following the financial crisis? Plos One. 2018;13(8):e0201215 [17p.].

3. Hong JH, Charles ST, Lee IS, Lachman ME. Perceived changes in life satisfaction from the past, present and to the future: a comparison of U.S. and Japan. Psychol Aging. 2019;34(3):317-29.

4. Ribeiro PCC, Almada DSQ, Souto JF, Lourenço RA. Permanence in the labour market and life satisfaction in old age. Ciênc Saúde Colet. 2018;23(8):2683-92.

5. Lan X, Xiao H, Chen Y, Zhang X. Effects of life review intervention on life satisfaction and personal meaning among older adults with frailty. J Psychosoc Nurs Mental Health Serv. 2018;56(7):30-6.

6. Veras RP, Oliveira M. Envelhecer no Brasil: a construção de um modelo de cuidado. Ciênc Saúde Colet. 2018;23(6):1929-36.

7. Campbell A, Converse PE, Rodgers WL. The quality of american life: perceptions, evaluations, and satisfactions. [no place]: Russell Sage Foundation;1976. p 171-208.

8. Mantovani EP, de Lucca S, Neri AL. Associações entre significados de velhice e bem-estar subjetivo indicado por satisfação em idosos. Rev Bras Geriatr Gerontol. 2016;19(2):203-22.

9. Cachioni M, Delfino LL, Yassuda MS, Batistoni SST, de Melo RC, Domingues MARC. Bem-estar subjetivo e psicológico de idosos participantes de uma Universidade Aberta à Terceira Idade. Rev Bras Geriatr Gerontol. 2017;20(3):340-52.

10. Parente L, Cunha M, Galhardo A, Couto M. Autocompaixão, bem-estar subjetivo e estado de saúde na idade avançada. Port J Behav Soc Res. 2018;4(1):3-13.

11. Instituto Brasileiro de Geografia e Estatística. Censo Demográfico 2010: resultados do universo. Rio de Janeiro: IBGE; 2010.

12. Veras RP, Dutra S. Perfil do idoso brasileiro: questionário BOAS. Rio de Janeiro: UNATI; 2008.

13. da Silva IT, Pinto Junior EP, Vilela ABA. Autopercepção de saúde de idosos que vivem em estado de corresidência. Rev Bras Geriatr Gerontol. 2014;17(2):275-87.
14. Vaz CT, Andrade ACS, Proietti FA, Xavier CC, Friche AAL, Caiaffa WT. A multilevel model of life satisfaction among old people: individual characteristics and neighborhood physical disorder. BMC Public Health. 2019;19(1):1-12.

15. Ghimire S, Baral BK, Karmacharya I, Callahan K, Mishra SR. Life satisfaction among elderly patients in Nepal: associations with nutritional and mental wellbeing. Health Qual Life Outcomes. 2018;16(118):1-10.

16. Ng ST, Tey NP, Asadullah MN. What matters for life satisfaction among the oldestold? Evidence from China. PLoS ONE. 2017;12(2):1-12.

17. John PDS, Mackenzie C, Menec V. Does life satisfaction predict five-year mortality in community-living older adults? Aging Ment Health. 2015;19(4):363-70.

18. Banhato EFC, Ribeiro PC, Guedes DV. Satisfação com a vida em idosos residentes na comunidade. Rev HUPE. 2018;17(2):16-24.

19. Róman XAS, Toffoletto MC, Sepúlveda JCO, Salfate SV, Grandón KLR. Factors associated to subjective wellbeing in older adults. Texto contexto Enferm. 2017;26(2):e5460015( 10p.).

20. Zhang H, Wang Y, Wu D, Chen J. Evolutionary path of factors influencing life satisfaction among chinese elderly: a perspective of data visualization. Data. 2018;3(35):1-10.

21. Meisenberg G, Woodley MA. Gender differences in subjective well-being and their relationships with gender equality. J Happiness Stud. 2015;16:1539-55.

22. Ostan R, Monti D, Gueresi P, Bussolotto M, Franceschi CC, Baggio G. Gender, aging and longevity in humans: an update of an intriguing/ neglected scenario paving the way to a genderspecific medicine. Clin Sci. 2016;130(19):1711-25.

23. Nunes BP, Batista SRR, de Andrade FB, de Souza Junior PRB, Lima-Costa MF, Fachini LA. Multimorbidade em indivíduos com 50 anos ou mais de idade: ELSI-Brasil. Rev Saúde Pública. 2018;52(2):1-12.

24. Silva PAB, Santos FC, Soares SM, Silva LB. Perfil sociodemográfico e clínico de idosos acompanhados por equipes de Saúde da Família sob a perspectiva do gênero. J Res Fundam Care. 2018;10(1):97-105.

25. Farías-Antúnez S, Lima NP, Bierhals IO, Gomes AP, Vieira LS, Tomasi E. Incapacidade funcional para atividades básicas e instrumentais da vida diária: um estudo de base populacional com idosos de Pelotas, Rio Grande do Sul, 2014. Epidemiol Serv Saúde. 2018;27(2):e2017290 (14p.). 
26. Sousa NFS, Lima MG, Cesar CLG, Barros MBA. Envelhecimento ativo: prevalência e diferenças de gênero e idade em estudo de base populacional. Cad Saúde Pública. 2018;34(11):e00173317 (16p.).

27. Celik SS, Celik Y, Hikmet N, Khan MM. Factors affecting life satisfaction of older adults in Turkey. Int J Aging Hum Dev. 2018;87(4):392-414.
28. dos Santos-Orlandi AA, de Brito TRP, Ottaviani AC, Rossetti ES, Zazzetta MS, Gratão ACM, et al. Perfil de idosos que cuidam de outros idosos em contexto de alta vulnerabilidade social. Esc Anna Nery. 2017;21(1):e20170013 (8 p.). 